\title{
Aspectos matemáticos, didáticos e pedagógicos das disciplinas de conteúdo matemático na licenciatura: um olhar a partir de teses e dissertações (2001-2017)
}

\author{
Amanda Larissa de Almeida \\ Rosana Giaretta Sguerra Miskulin
}

\begin{abstract}
Resumo: Por meio do presente artigo, discute-se aspectos matemáticos, didáticos e pedagógicos das disciplinas de conteúdo matemático do curso de Licenciatura em Matemática, a partir de um recorte de uma pesquisa de Mestrado, a qual constituiu-se como um estudo de 26 teses e dissertações, com objetivo de analisar e evidenciar articulações entre os seus resultados e o campo de formação de professores. Tais teses e dissertações foram mapeadas em dois momentos distintos: aquelas produzidas entre os anos de 2001 e 2012 foram mapeadas a partir do corpus de pesquisa do projeto universal "Mapeamento e estado da arte da pesquisa brasileira sobre o professor que ensina Matemática", e teses e dissertações produzidas entre 2013 e 2017 mapeadas no Catálogo da CAPES. Para analisar os resultados dessas pesquisas utilizamos alguns conceitos da Análise de Conteúdo e nos baseamos em referenciais teóricos sobre formação inicial de professores de Matemática e formação matemática do professor. Nesse contexto, apresentamos a discussão de uma categoria, a qual evidencia a possibilidade de articulação entre as disciplinas de conteúdo matemático e a prática do futuro professor. por meio de metodologias como o Trabalho com Projetos, Modelagem Matemática e uso de Softwares. Tais abordagens constituem-se como um caminho para o desenvolvimento dessas disciplinas na licenciatura, uma vez que propiciam a exploração, investigação, visualização e aplicações dos conceitos, além de discussões sobre o ensino da Matemática na Educação Básica.
\end{abstract}

Palavras-chave: Disciplinas de conteúdo matemático. Licenciatura em Matemática. Práticas formativas.

Amanda Larissa de Almeida

Mestre em Educação Matemática pela

Universidade Estadual Paulista

(UNESP), campus Rio Claro. Professora

da Escola Estadual Raimundo Corrêa,

amandalaah95@.gmail.com

Rosana Giaretta Sguerra Miskulin

Doutora em Educação pela Universidade

Estadual de Campinas (UNICAMP)

Professora do Programa de Pós-

Graduação em Educação Matemática da

Universidade Estadual Paulista

(UNESP), campus Rio Claro, São Paulo,

Brasil. $\bowtie$ rosana.miskulin@unesp.br

Recebido em 30/01/2019

Aceito em 01/03/2019

Publicado em 01/09/2019
Minas Gerais, Brasil.

\section{Mathematical, didactic and pedagogical aspects of the subjects of mathematical content in graduation: a look for theses and dissertations (2001-2017)}

Abstract: In this article, we discuss mathematical, didactic and pedagogical aspects of mathematical content in mathematics degree courses. The authors studied 26 theses / dissertations on mathematical content subjects, aiming to analyze and look for evidence in relation to the articulation between their results and the field of teacher training. These theses and dissertations were mapped into two distinct moments: those produced between 2001 and 2012 were mapped from the research corpus of the Universal Project "Mapping and State of the Art of Brazilian Researchin Regards to the Teacher Who Teaches Mathematics" and the theses and dissertations carried out between 2013 and 2017 were mapped through the Catalog of Capes. To analyze the results of these works, we used some concepts from the theory of content analysis and we base ourselves on theoretical references about the initial formation of teachers of mathematics and the mathematical formation of the teacher. In this context, we present the discussion of a category, which highlights the possibility of the articulation between the mathematical content disciplines and a future teacher's practice; by means of methodologies like work with projects, mathematical modeling and use of software. These approaches constitute a way for the development of these disciplines in the licenciatura (math teacher degree program), since they facilitate exploration, investigation, visualization and applications of the concepts, and discussion about the teaching of mathematics in basic education.

Keywords: Mathematical content disciplines. Degree in Mathematics. Training practices. 


\section{Aspectos matemáticos, didácticos y pedagógicos de las disciplinas de contenido matemático en la Licenciatura: una mirada a partir de tesis y disertaciones (2001-2017)}

Resumen: Por medio del presente artículo, se discute aspectos matemáticos, didácticos y pedagógicos de las disciplinas de contenido matemático del curso de Licenciatura en Matemáticas, a partir de un recorte de una investigación de Maestría, como un estudio de 26 tesis/disertaciones sobre disciplinas de contenido matemático, con el objetivo de analizar y evidenciar articulaciones entre sus resultados y el campo de formación de profesores. Estas tesis y disertaciones fueron mapeadas en dos momentos distintos: aquellas producidas entre los años 2001 y 2012 fueron mapeadas a partir del corpus de investigación del Proyecto Universal "Mapeamiento y Estado del arte de la investigación brasileña sobre el profesor que enseña Matemáticas" y las tesis y disertaciones realizadas entre 2013 y 2017 fueron mapeadas a través del Catálogo de la CAPES. Para analizar los resultados de esas investigaciones utilizamos algunos conceptos de la teoría del Análisis de Contenido y nos basamos en referenciales teóricos sobre formación inicial de profesores de Matemáticas y formación matemática del profesor. En este contexto, presentamos la discusión de una categoría, la cual evidencia la posibilidad de articulación entre las disciplinas de contenido matemático y la práctica del futuro profesor. Por medio de metodologías como el Trabajo con Proyectos, Modelado Matemático y uso de Softwares. Estos enfoques se constituyen como un camino para el desarrollo de estas disciplinas en la Licenciatura, ya que propician la exploración, investigación, visualización y aplicaciones de los conceptos, además de discusiones sobre la enseñanza de las Matemáticas en la Educación Básica.

Palabras clave: Disciplinas de contenido matemático. Licenciatura en Matemáticas. Prácticas de entrenamiento.

\section{Introdução}

A formação de professores no Brasil foi implementada no final do século XIX com os cursos normais e, no início do século XX, com a criação das Faculdades de Filosofia, Ciências e Letras (CASTRO, 1974). Inicialmente, os cursos eram constituídos a partir de um modelo de três anos de bacharelado com matérias especificas de Matemática e por mais um ano dedicado à formação pedagógica, também popularmente conhecido como modelo 3 + 1 (MOREIRA e DAVID, 2005).

Desde então, essa realidade vem sendo debatida e modificada por meio de políticas públicas como as Leis de Diretrizes e Bases e as Diretrizes Curriculares Nacionais para a Formação de Professores, dentre as quais citamos mudanças como carga horária dos cursos; reestruturação e criação de disciplinas; ampliação de disciplinas pedagógicas como Psicologia da Educação, Práticas de Ensino e Estágios; estágios, entre outras. No entanto, os cursos de licenciatura ainda enfrentam problemáticas que não foram totalmente superadas no decorrer dos anos, como por exemplo, a desarticulação entre as disciplinas especificas e pedagógicas e entre a formação e a prática docente na Educação Básica (GATTI, 2010).

Estudos como Moreira e David (2005), Fiorentini (2005), Klein (2009) e Moreira (2012) denunciam um distanciamento entre a Matemática abordada na formação inicial e aquela que 0 
professor "precisa saber" para ensinar. Além disso, o modo como as disciplinas de conteúdo matemático são organizadas e lecionadas nos cursos de formação de professores, não privilegia a investigação e discussão dos conceitos matemáticos ou então não tem sido mobilizadas discussões acerca dos processos de ensino e de aprendizagem da Matemática.

Diante desse panorama nacional, a pesquisa de Mestrado, da qual apresentamos neste artigo um recorte da análise, busca contribuir com essa discussão e oferecer subsídios para novas discussões e possibilidades para o desenvolvimento das disciplinas de conteúdo matemático (Cálculo Diferencial e Integral, Análise, Álgebra, entre outras) no contexto do curso de Licenciatura em Matemática. Para isso, foram analisados um conjunto de 26 teses e dissertações que investigaram uma ou mais disciplinas de conteúdo matemático no contexto da licenciatura e tem como objetivo analisar e evidenciar articulações entre os resultados dessas pesquisas e aspectos conceituais do campo de formação inicial de professores de Matemática.

Tais teses e dissertações foram desenvolvidas entre os anos de 2001 a 2017 nos programas brasileiros de pós-graduação em Educação, Educação Matemática e Ensino de Matemática. Para analisar essas pesquisas, utilizamos conceitos da Análise de Conteúdo (BARDIN, 1977) e elencamos três categorias de análise: (1) a formação Inicial de professores de Matemática: aspectos estruturais e conceituais, (2) disciplinas de conteúdo matemático: aspectos matemáticos, didáticos e pedagógicos, e suas inter-relações com a prática pedagógica do professor e (3) trabalho docente do professor formador: aspectos didáticos, metodológicos e epistemológicos.

Para este artigo, focamos na apresentação e discussão da segunda categoria, na qual são apresentadas diferentes práticas pedagógicas desenvolvidas pelas teses e dissertações analisadas, no contexto de disciplinas de conteúdo matemático e associadas à utilização de softwares e abordagens como o Trabalho com Projetos, Modelagem Matemática, entre outras.

\section{Disciplinas de conteúdo matemático na licenciatura}

Ao nos referirmos às disciplinas de conteúdo matemático do curso de Licenciatura em Matemática, estamos considerando aquelas disciplinas que abordam os conteúdos matemáticos recomendados pelas Diretrizes Curriculares Nacionais para os Cursos de Matemática (BRASIL, 2001). Estes conteúdos são Cálculo Diferencial e Integral, Álgebra Linear, Fundamentos de Análise, Fundamentos de Álgebra, Fundamentos de Geometria e Geometria Analítica. Além desses, há conteúdos que não são recomendados pelas diretrizes, mas que, a critério da 
instituição, podem ser incluídos no rol das disciplinas do curso, como, por exemplo, Estatística, Equações Diferenciais, entre outras.

Cada um dos tópicos pode ser organizado em uma ou mais disciplinas ao longo do curso, como o Cálculo Diferencial e Integral, que comumente é distribuído em Cálculo I, Cálculo II, Cálculo III e até Cálculo IV ou V. Essa organização também acontece com os Fundamentos de Álgebra que se dividem em Álgebra Linear I e II e Estruturas Algébricas, e com os Fundamentos de Geometria que comumente são subdivididos em Plana, Espacial e Euclidiana.

Embora essas disciplinas abordem conteúdos matemáticos, elas não são ausentes do objetivo de formar o professor (GRILO, BARBOSA e LUNA, 2015). De acordo com Fiorentini (2005), ao mesmo tempo que em disciplinas pedagógicas podem ser discutidos conceitos e procedimentos matemáticos, nas disciplinas de conteúdo matemático, o professor, ainda que não perceba, ensina modos de formar pessoas e de ser professor de Matemática, os quais o licenciando poderá reproduzir na sua futura prática docente.

Ponte (2014) ressalta que tanto essas disciplinas quanto as pedagógicas são necessárias e importantes à formação inicial, oferecendo contributos para 0 trabalho do professor enquanto docente dessa disciplina na Educação Básica. Entretanto, de acordo com o autor, para aprender a ensinar Matemática não basta aprender conhecimentos previamente sistematizados em disciplinas isoladas, "é necessário integrá-los tendo em atenção as necessidades decorrentes das situações de prática que o professor é chamado a desempenhar" (PONTE, 2014, p. 350). Segundo Pais (2007), não faz sentido conceber as disciplinas específicas de forma isolada dos aspectos didáticos, da mesma maneira como também não faz sentido idealizar as disciplinas pedagógicas desprovidas de vínculos com as raízes epistemológicas da Matemática.

Todavia, essas concepções ainda não predominam de modo significativo se pensarmos na realidade dos cursos de licenciatura. Para Moreira (2012), embora a Licenciatura em Matemática tenha saído do esquema $3+1$, continua mantendo essa lógica estruturante ao propor uma separação entre disciplinas de conteúdo matemático e as disciplinas pedagógicas. Para 0 autor,

[...] as disciplinas de conteúdo são projetadas e executadas independentemente das outras disciplinas, as que se referem ao trabalho de ensino, que são, em geral, concebidas e executadas nas Faculdades de Educação. Essa separação baseia-se na mesma lógica que orientou a estruturação desses cursos no sistema $3+1$ [...]. (MOREIRA, 2012, p. 1140). 
O autor discute, ainda, que a formação matemática oferecida na formação inicial precisa tomar como referência a prática docente do professor da Educação Básica. Para que isso aconteça, notamos que são imprescindíveis ações que vão além de restruturação de programas curriculares ou ementas (BENITES, 2013), sendo importante também uma mudança de concepção sobre o papel da Matemática na licenciatura e sobre como essa formação pode ser realizada de modo a melhor contribuir na formação do professor.

Pensar desse modo não significa que a formação deva se reduzir ao ensino da Matemática escolar, abordando apenas os conteúdos que o professor irá ensinar e desconsiderar a importância e contribuição da Matemática Acadêmica. Para Moreira (2012), o que acontece é que a formação do professor de Matemática precisa ser pensada levando em consideração a especificidade da prática docente, assim como o médico, o engenheiro e o arquiteto, por exemplo, precisam de um olhar único para suas profissões.

Fiorentini (2005) sugere que, ao lecionar disciplinas de conteúdo matemático, o professor universitário adote o ensino por meio de projetos de Modelagem Matemática, Investigações Matemáticas, entre outros. A Modelagem Matemática, de acordo com Barbosa (2001), pode ser compreendida como um ambiente de aprendizagem no qual os alunos são convidados a questionar e investigar situações com referência à realidade por meio da Matemática. Por sua vez, a Investigação Matemática se caracteriza por atividades em que os alunos vão fazendo suas próprias descobertas, sem um caminho previamente delineado, em que o objetivo é chegar no resultado (PONTE, BROCARDO e OLIVEIRA, 2003; MISKULIN, ESCHER e SILVA, 2007).

Para Fiorentini (2005), essas formas de viver a Matemática contribuem não só para uma sua apropriação compreensiva e histórico-crítica, como ajudam a formar didáticopedagogicamente o professor. E ainda,

\footnotetext{
[...] se, de um lado, pode haver uma perda em relação à sistematização e formalização rigorosa dos conceitos matemáticos a serem ensinados e aprendidos, de outro, 0 futuro professor viverá um ambiente rico em produção e negociação de significados, aproximando-se, assim, do movimento de elaboração/construção do saber matemático (FIORENTINI, 2005, p.112)
}

Citamos também outras metodologias como a Resolução de Problemas (ONUCHIC e MORAIS, 2013), a Sala de Aula Invertida (VALENTE, 2014), o uso de Tecnologias Digitais (MISKULIN e SILVA, 2010) entre outras, como potenciais para o desenvolvimento de conceitos matemáticos e sobre o ensino. De acordo com Passos et al. (2006, p. 215), "práticas reflexivas, 
investigativas e colaborativas em ambientes coletivos de aprendizagem docente constituem uma poderosa tríade catalisadora do desenvolvimento profissional dos professores de Matemática".

Entretanto, é importante destacar que essas formas de vivenciar a Matemática precisam estar associadas com uma preocupação do professor formador em oferecer uma formação aos licenciandos que considere a prática docente do professor. O formador assume papel importante tanto no que se refere às suas concepções de ensino, quanto no modo como ele organiza e desenvolve suas aulas. Para Fiorentini (2005),

\footnotetext{
o formador de professores de Matemática precisa constituir-se um profissional com características de formador-pesquisador que assume a docência como função principal de seu trabalho na universidade e busque desenvolver pesquisas que dêem o suporte necessário para a realização e desenvolvimento dessa função (p.114).
}

Esta questão também é abordada por Moreira (2012), ao considerar que "não basta ter competência como matemático profissional para ter competência para formar professores de matemática" (p. 1148). Para o pesquisador, o trabalho com a Matemática do professor demanda um trânsito permanente entre a área do conteúdo e a área pedagógica, apagando as fronteiras que os separam e reconstituindo-os em um único campo. Deste modo, com a formação que tiveram, os formadores não estão qualificados adequadamente para operar o diálogo necessário entre esses dois campos nas ações de formação.

Com essa discussão, consideramos que repensar a formação do formador é como um caminho que também precisa ser trilhado. $E$ ainda, mais do que isso, são necessárias políticas públicas para a licenciatura que considerem a especificidade do trabalho docente em Matemática na Educação Básica, pois é preciso espaço e condições para que o professor formador dialogue com a prática docente e adote práticas diferenciadas no processo de formação dos licenciandos.

Existem ainda outras questões que precisam ser refletidas e estudadas para que a formação inicial de professores de Matemática contribua mais significativamente para o campo de atuação deste profissional. Ainda assim, entendemos que discutir acerca da formação nas disciplinas de conteúdo matemático é um passo nesta direção.

\section{Percurso metodológico: da constituição do corpus de pesquisa aos procedimentos de análise dos dados}

A pesquisa de mestrado tem natureza qualitativa, a qual, para Goldenberg (2004), não se preocupa em produzir generalizações, ao contrário, objetiva uma compreensão profunda do 
fenômeno investigado, enfatizando suas particularidades e significados dentro de um determinado contexto. Nessa perspectiva, a denominamos de estudo interpretativo visto que nosso esforço está em integrar resultados das teses e dissertações e analisar suas possíveis contribuições para 0 campo da formação de professores.

As teses e dissertações foram mapeadas em dois momentos distintos: aquelas produzidas entre os anos de 2001 e 2012 foram mapeadas a partir do corpus de pesquisas do projeto universal "Mapeamento e Estado da arte da pesquisa brasileira sobre o professor que ensina Matemática" (FIORENTINI, PASSOS e LIMA, 2016). Já as teses e dissertações realizadas entre 2013 e 2017 foram levantadas no Catálogo de Teses e Dissertações da Coordenação de Aperfeiçoamento de Pessoal de Nível Superior (CAPES). Em ambos contextos, o critério utilizado consistiu na busca a partir de termos como "formação matemática", "disciplinas especificas" e pelos nomes das disciplinas.

Este recorte de tempo permitiu a constituição de um conjunto de 5 Teses de Doutorado e 21 Dissertações de Mestrado (Figura 1); com isso realizamos a articulação de diversos resultados de pesquisas sobre disciplinas de conteúdo matemático.

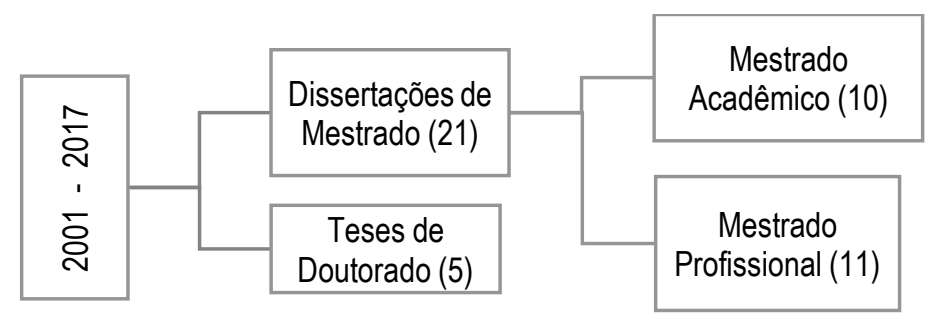

Figura 1: Corpus de análise da pesquisa (Elaboração das Autoras)

Essas pesquisas foram produzidas em doze instituições de ensino superior (IES) de seis estados brasileiros: Ceará, Minas Gerais, São Paulo, Paraíba, Paraná, Rio de Janeiro e Rio Grande do Sul, com destaque para a Universidade Estadual Paulista (UNESP), a Pontifícia Universidade Católica de São Paulo (PUC-SP), a Universidade Federal de Ouro Preto (UFOP) e a Universidade Federal de Juiz de Fora (UFJF), que apresentam três ou mais trabalhos desenvolvidos em seus programas de pós-graduação em Educação ou em Educação Matemática.

Todas as teses e dissertações possuem abordagem metodológica de pesquisa qualitativa. Em relação aos dados das pesquisas, são constituídos por meio de um ou mais instrumentos: desenvolvimento de atividades, experimentos de ensino, projetos ou sequência didática (10 teses/dissertações), realização de entrevistas e/ou aplicação de questionários (21 teses/dissertações), análise de livros didáticos e/ou documentos de cursos (5 teses/dissertações). 
Quando à fonte de dados, esta provém de entrevistas e/ou questionários; os sujeitos fazem parte de um ou dois dos seguintes grupos: licenciandos em Matemática, professores da Educação Básica, professores que atuam no curso de Licenciatura ou professores autores de livros didáticos. Algumas pesquisas que coletaram os dados dessa forma objetivaram analisar concepções sobre o ensino da disciplina investigada ou organização do programa da disciplina, ou ainda a contribuição para a formação do professor e articulação com a Educação Básica. Outras pesquisas ainda desenvolveram atividades que abordavam alguns conteúdos da disciplina investigada a partir de diferentes recursos como uso de softwares, trabalho com projetos, modelagem matemática, entre outros.

O conjunto de pesquisas que coletaram seus dados por meio de análise de documentos, livros didáticos ou analise de currículos de cursos de Licenciatura em Matemática, de modo geral, apresentaram o interesse de analisar como o curso ou uma determinada disciplina estava organizada, quais seus objetivos, quais conteúdos são privilegiados, quais referências bibliográficas são utilizadas. Há ainda um grupo de pesquisas que associaram entrevistas com análise de documentos ou entrevistas com observação participante e anotação de diário de campo, como fontes de dados na investigação que realizaram.

Das disciplinas de conteúdo matemáticos que aparecem como foco ou contexto de investigação, destacamos a Análise Matemática; Geometria Plana, Espacial ou Analítica; Álgebra Linear; Cálculo Diferencial e Integral; Equações Diferenciais; e Estatística. A investigação dessas disciplinas, na maioria das pesquisas, trouxe uma preocupação explícita com a formação de professores de Matemática e basearam-se em referenciais teóricos sobre o tema, como por exemplo, conhecimento matemático e saberes docentes.

Para analisar os resultados dessas pesquisas, utilizamos alguns conceitos da Análise de Conteúdo nas concepções de Bardin (1977), a qual é composta por três fases: (1) Pré-Análise, (2) Exploração do Material e (3) Tratamento dos resultados, Inferência e Interpretação. Destacamos 0 uso deste referencial pela possibilidade de organização e interpretação dos dados que a abordagem oferece e também por ser uma perspectiva do Grupo de Pesquisa em Processos de Formação e Trabalho Docente dos Professores de Matemática (Grupo de Formação de Professores) do Programa de Pós-Graduação em Educação Matemática da Universidade Estadual Paulista (UNESP), campus Rio Claro, em São Paulo, a qual a presente pesquisa está inserida. 


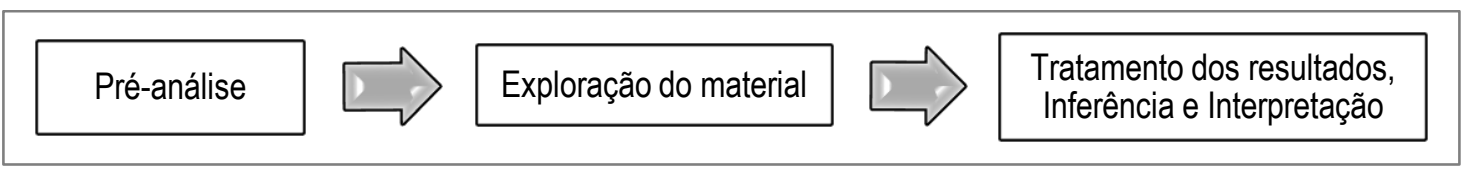

Figura 2: llustração das fases da Análise de Conteúdo (Baseado nas fases da Análise de Conteúdo de Laurence Bardin (Elaboração das Autoras)

A Pré-Análise compreende a constituição do corpus de trabalho, formulação e reformulação de hipóteses ou pressupostos, acompanhados por uma leitura flutuante dos dados, proporcionando ao pesquisador um contato direto com o material de campo, em que podem surgir a relação entre as hipóteses ou pressupostos iniciais, as hipóteses emergentes e as teorias relacionadas ao tema.

A fase de Exploração do material "consiste essencialmente de operações de codificação, desconto ou enumeração, em função de regras previamente formuladas" (BARDIN, 1977, p. 101). A escolha das Unidades de Contexto (excertos significativos das mensagens) permite a identificação das Unidades de Registro (palavra, tema, tópico) e, a partir das articulações entre as UR, são delimitados os Eixos Temáticos. Já na terceira fase, o pesquisador constitui as Categorias de Análise e interpreta os dados da pesquisa.

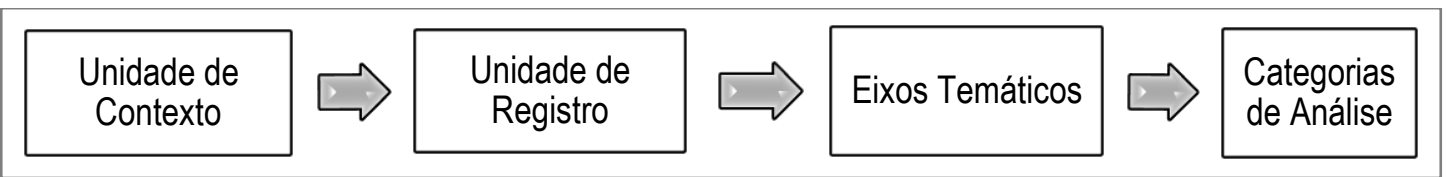

Figura 3: Elementos resultantes das etapas da Análise de Conteúdo (Elaboração das Autoras)

Assim, a partir dos dados coletados, produzimos fichamentos de leitura contendo informações das teses/dissertações como palavras-chave, objetivos, questão de investigação, procedimentos metodológicos, sujeitos da pesquisa, resultados, considerações finais, referencial teórico e uma justificativa explicitando o motivo pelo qual o trabalho foi delimitado para análise.

Partindo dos resultados das pesquisas, foram identificados trechos significativos que deram origem às Unidades de Contexto. Em seguida, após sucessivas leituras das Unidades de Contexto e muitas idas e vindas, foram identificadas as Unidades de Registro. Com a identificação das Unidades de Registro, realizamos um processo de análise das confluências e divergências entre elas para identificar os Eixos Temáticos 1 .

Por fim, realizamos uma articulação entre os Eixos Temáticos, o objetivo e o problema da pesquisa e constituímos três categorias de análise da pesquisa, conforme apresentamos na

\footnotetext{
${ }^{1}$ Ressaltamos que no Grupo de Pesquisa em Formação de Professores, liderado pela Profa. Dra. Rosana Giaretta Sguerra Miskulin, utiliza a fase de constituição dos Eixos Temáticos, ultrapassando assim as fases de Análise de Conteúdo de Bardin - Unidades de Registro, Unidades de Contexto e Categorias de Análise.
} 
Introdução. Por fim, descrevemos cada uma das categorias estabelecendo um diálogo entre os excertos dos resultados das teses/dissertações e o referencial teórico da pesquisa.

De modo geral, os resultados das teses e dissertações apresentam contribuições em relação a estrutura do curso de Licenciatura em Matemática, políticas públicas relacionadas à formação, trabalho docente do professor formador, além de apresentar diversas práticas pedagógicas no contexto das disciplinas de conteúdo matemático, as quais apresentamos na próxima seção.

\section{0 que nos dizem as teses e dissertações: aspectos matemáticos, didáticos e pedagógicos das disciplinas de conteúdo matemático}

Para evidenciarmos os aspectos matemáticos, didáticos e pedagógicos das disciplinas de conteúdo matemático, presentes nas teses e dissertações analisadas, elencamos, no presente artigo, a categoria denominada Disciplinas de conteúdo matemático: aspectos conceituais, didáticos e pedagógicos, e suas inter-relações com a prática pedagógica do professor. Esta categoria originou-se de um movimento dialógico entre seis eixos temáticos: potencialidades didáticas e pedagógicas do Trabalho com Projetos; potencialidades didáticas e pedagógicas da utilização de TIC; potencialidades da utilização da escrita em aulas de Matemática; potencialidades didáticas e pedagógicas da Modelagem Matemática; potencialidades didáticas e pedagógicas da investigação matemática; e, por último, aspectos conceituais de disciplinas de conteúdo matemático.

A partir do movimento de articulação entre os eixos temáticos, discutimos sobre os limites e possibilidades de diferentes práticas pedagógicas e/ou abordagens metodológicas no contexto de disciplinas de conteúdo matemático, desenvolvidas ou discutidas pelas teses e dissertações analisadas.

No âmbito do Cálculo Diferencial e Integral, Gonçalves (2012) desenvolveu atividades investigativas com auxílio do software GeoGebra sobre aplicações de derivadas. Para a pesquisadora, a experiência contribuiu para a ressignificação dos conceitos por parte dos alunos, levando-os a repensar e refletir sobre eles, como mostram os excertos a seguir.

As atividades investigativas, elaboradas na perspectiva da descoberta guiada, contribuíram para ressignificar os conhecimentos dos alunos em relação às aplicações das derivadas. Consideramos que essas contribuições foram proporcionadas pelo ambiente de investigação criado pelas atividades, em que os alunos foram levados a: explorar as situações, formular questões, testar e verificar a veracidade de suas 
afirmações, verbalizar suas ideias, registrar suas estratégias e justificar seu pensamento (GONÇALVES, 2012, p. 93).

[...] a realização das atividades investigativas contribuiu para uma ressignificação dos conhecimentos dos alunos, inicialmente construídos em sala de aula, a partir da oportunidade que eles tiveram de repensar/refletir sobre os conceitos envolvidos nas diversas aplicações das derivadas abordadas nas atividades (GONÇALVES, 2012, p. 105).

Essa experiência mostra que uma disciplina como o Cálculo Diferencial e Integral pode ser desenvolvida de modo que os alunos explorem e investiguem os conceitos envolvidos, diferentemente do modo como comumente acontece nos cursos de licenciatura. Além disso, como mostra o trecho a seguir, a pesquisadora discute sobre a contribuição do uso do software:

Evidenciamos também que um ambiente informatizado é propício para a realização de atividades investigativas e possibilita a construção do conhecimento matemático, por permitir aos alunos modelar problemas, fazer simulações e visualizar situações, o que muitas vezes não seria possível sem as ferramentas computacionais. Destacamos ainda que com a dinamicidade proporcionada por esse ambiente, o conhecimento matemático deixa de ter um caráter estático e permite maior interação dos alunos com o conhecimento que está sendo construído (GONÇALVES, 2012, p. 95).

Souza (2015) também pontua contribuições da utilização da tecnologia no contexto da disciplina de Cálculo Diferencial e Integral, destacando a importância desses recursos e da contextualização, como mostram os excertos a seguir:

[...] podemos ratificar a importante contribuição das TIC no processo de ensinar Cálculo Diferencial e Integral, potencializando a visualização, a compreensão e a verificação de conjecturas e conceitos, libertando do recurso da memorização, aquele em que a abstração constituía impedimento para a aprendizagem (SOUZA, 2015, p. 223).

[...] a disciplina Cálculo Diferencial e Integral I não pode ser apresentada de maneira descontextualizada, porque, assim, corre o risco de perder o seu significado e tornarse obsoleta, principalmente diante do avanço da Tecnologia, permeando todos os campos de estudo, hoje, em nossa sociedade (SOUZA 2015, p. 232).

Mais especificamente, nas aulas de Cálculo Diferencial e Integral I, para os alunos de Licenciatura em Matemática, os professores precisariam desenvolver práticas para além da transmissão pura e simples dos conceitos e teoremas e listas intermináveis de exercícios de aplicação e treinamento algébricos. Práticas que considerem: Estudos em Grupos, Diálogos TIC, Recursos diferenciados, fatos e Projetos, aspectos históricos, Comunidades de estudos colaborativos desenvolvidos com uma postura investigativa (SOUZA 2015, p. 232).

As pesquisas de Gonçalves (2012) e Diogo (2015) mostram que uma disciplina como 0 Cálculo Diferencial e Integral pode ser desenvolvida de forma que os alunos explorem e investiguem os conceitos matemáticos, diferentemente do modo como comumente acontece nos cursos de licenciatura. 
Também utilizando o software GeoGebra, Mazzi (2014) apresenta uma prática no contexto da disciplina de Análise Matemática, que consistiu no desenvolvimento de atividades relacionadas à convergência de sequências numéricas. 0 pesquisador destaca a contribuição do uso do software na investigação dos conceitos e mudança qualitativa da interação entre as alunas, como apresentados nos excertos abaixo:

[...] a utilização de um software no ensino da disciplina Análise pode trazer contribuições para a aprendizagem dos alunos. Nota-se que as alunas-com-geogebra, a partir da experimentação-com-tecnologia, elaboram questionamentos e os investigam imediatamente, obtendo um feedback rápido do software (MAZZI, 2014, p. 105).

Um ambiente de investigação com tecnologia, no qual o professor não tem controle total sobre as atividades, pode deixar os alunos mais confortáveis e incentivá-los a questionar. $\mathrm{O}$ uso da tecnologia permitiu que fossem elaboradas e refutadas algumas conjecturas, como as apresentadas acima. Mais do que isso, ela permitiu uma discussão e reflexão por parte das alunas quanto ao resultado investigado (MAZZI, 2014, p. 109).

Analisando os dados produzidos pelo coletivo pensante alunas-com-geogebra, percebeu-se que o software em questão não assumiu apenas papéis relacionados aos conceitos investigados. Houve momentos nos quais discussões emergiram e que não possuíam relação direta com os tópicos matemáticos investigados. Borba (2005) chama atenção para a mudança qualitativa nas discussões ocorridas em ambientes onde a tecnologia está inserida e defende que as mídias são primordiais nos processos de comunicação (MAZZI, 2014, p. 115).

Mazzi (2014) chama a atenção para o fato de que a tecnologia foi utilizada em uma disciplina rigorosa como a Análise Matemática e sugere ainda que essa prática se torne frequente avaliando suas contribuições:

Pode-se até considerar contra intuitivo o uso de tecnologias em uma disciplina considerada tão rigorosa como esta, no entanto, se essa utilização indica uma possibilidade de melhor compreensão dos conceitos envolvidos nessa disciplina, defendo que esses usos devem se tornar cada vez mais frequentes (MAZZI, 2014, p. 120).

Fiorentini (2005) discute que em disciplinas de conteúdo específico, os futuros professores aprendem, além do conteúdo, modos de ser professor e ensinar Matemática. Assim, ao vivenciarem o uso da tecnologia na investigação dos conceitos como aconteceu na pesquisa de Mazzi (2014), os licenciandos poderão levar essa experiência para sua prática docente.

Mais uma vez, o software GeoGebra foi utilizado por Santos (2011), no contexto da disciplina de Geometria Analítica, para o desenvolvendo de atividades exploratórias sobre os conceitos de Retas, Circunferências e Cônicas. Para o pesquisador, as atividades, que se tornaram dinâmicas pelo uso do software, contribuíram para a autonomia dos alunos e 
complementaram os assuntos abordados nas aulas, colaborando também para o desenvolvimento profissional dos professores.

Percebemos nesses depoimentos que, ao utilizarmos a estratégia do uso do computador, esse ambiente de aprendizagem enriqueceu-se e nos mostra, dentre outras possibilidades: uma nova forma de aprendizagem; desenvolvimento da autonomia do aprendiz; o aluno aprende fazendo o que antes aprendia ouvindo e repetindo nos exercícios; uma conexão entre o algébrico e geométrico; um sentido de complementaridade entre os assuntos estudados em sala de aula e os exercícios propostos nas atividades, com 0 destaque para a dinamicidade das atividades (SANTOS, 2011, p.126).

Em relação às contribuições para o desenvolvimento profissional do futuro Professor de Matemática que deseja utilizar as Tecnologias da Informação e Comunicação na Educação Matemática em sua prática pedagógica, nossos participantes foram unânimes em afirmar que a utilização das TICEM tanto reforça o papel da linguagem gráfica, como inova nas representações (PONTE e OUTROS, 2003; ALLEVATO, 2005). Por fim, destacamos a contribuição de nossas atividades para a autonomia e amadurecimento de futuros Professores de Matemática. Como exemplo, citamos 0 desafio proposto aos participantes, na última atividade, de criar livremente uma atividade exploratória com parábolas. Se, por um lado, algumas atividades criadas nos pareceram fortemente inspiradas pelas atividades realizadas, por outro lado, alguns grupos demonstraram criatividade e ousadia, evidenciando um notável crescimento / desenvolvimento. Dessa forma, acreditamos ter contribuído com a formação inicial de nossos participantes e dando-lhes uma visão mais abrangente e inovadora sobre 0 significado e importância sobre uso do computador na prática pedagógica (SANTOS, 2011, p. 131).

Santos (2011) destaca ainda a mudança provocada na sala de aula quando se utiliza recursos tecnológicos. Com um ambiente informatizado, o professor deixa de ser o centro do processo, como acontece no modelo tradicional, e os alunos são chamados a aprender a aprender, como vemos no excerto a seguir:

Outro aspecto a ser destacado a partir de nossas observações, de nosso referencial teórico e, por fim, das discussões geradas entre os participantes, refere-se à relação entre a aula no modelo tradicional e a aula no laboratório de informática. No modelo tradicional, o professor é o centro do processo. O estudante recebe a informação pronta e acabada. Analisa-se o resultado final, esquecendo-se, por vezes, do processo. Quando o processo é viabilizado em um ambiente onde o computador é uma ferramenta auxiliar no processo de construção do conhecimento, segundo afirma Almeida (2000), requerer-se uma preparação do professor no sentido de que ele possa desenvolver nos seus alunos a capacidade para aprender a aprender; ter autonomia para selecionar as informações pertinentes à sua ação; refletir sobre uma situação problema; refletir sobre os resultados obtidos; levantar e testar hipóteses. Acreditamos que a realização de nossas atividades num laboratório de informática contribuiu para que os participantes desenvolvessem sua capacidade de "aprender a aprender", conforme notamos nas atividades que trouxeram ideias/definições ainda não trabalhadas na sala de aula (SANTOS, 2011, p. 127).

A utilização do GeoGebra também esteve presente na pesquisa de Schultz (2015) que, ao propor que na disciplina de Métodos Matemáticos os licenciandos desenvolvessem projetos de 
Modelagem Matemática, eles o utilizaram como um auxílio e facilitador no processo, como vemos a seguir:

Quanto aos recursos tecnológicos utilizados pelos grupos, percebe-se que todos utilizaram o software GeoGebra, o que ocorreu, segundo os grupos, por ser mais familiar a eles, além de disponibilizar uma visualização melhor dos gráficos, apresentando subsídios suficientes para o desenvolvimento dos projetos. Segundo os grupos, a possibilidade de utilização dos recursos tecnológicos auxiliou e facilitou a compreensão nos projetos (SCHULTZ, 2015, p. 95).

Schultz (2015) discute que a abordagem de projetos constituiu como um desafio para os alunos na medida que tiveram que pensar além de teoremas e regras para fazer as aplicações dos conceitos:

Quanto ao aspecto formativo do aluno, pode-se dizer que os projetos de Modelagem Matemática contribuíram para que enfrentassem atividades que nunca tinham experimentado, fazendo com que pensassem, não na maneira como iriam aplicar a Matemática, ou seja, que teoremas ou regras seriam aplicadas para resolver esta questão, mas tivessem de ir além, pensando em um tema, em situações-problema e verificando se era possível a aplicação dos conteúdos estudados para resolver a problemática proposta, além de auxiliar nas suas futuras práticas docentes (SCHULTZ, 2015, p. 97).

As contribuições da Modelagem Matemática também são apresentadas por Domingos (2016), que investigou como os alunos desenvolvem suas habilidades e atitudes para a prática da sala de aula no contexto da Modelagem Matemática relacionado à metodologia da Resolução de Problemas em um curso sobre Equações Diferenciais, como mostram os excertos a seguir:

O estudo revelou que, trabalhando através de situações-problema no contexto da Modelagem Matemática em uma perspectiva que considera o aluno como parceiro na construção de um novo conhecimento é um caminho promissor para o ensinoaprendizagem de Matemática e Física (DOMINGOS, 2016, p.175).

Percebeu-se que os futuros professores, quando têm a oportunidade de se expressar e de participar ativamente nas atividades desenvolvidas em sala de aula, desenvolverão atitudes e habilidades para quando vierem a atuar como docentes. Não foi possivel analisar todos os alunos atuando na prática, pelo fato de apenas alguns já exercerem a função docente. Contudo, aqueles que ainda não atuavam como professores, foram questionados a todo o momento, sobre como trabalhariam determinados temas da realidade utilizando os conteúdos de Física e de Matemática. Mesmo com esses alunos que ainda não estejam atuando em sala de aula, foi possível identificar, a partir de suas falas e dedicação, alguns indícios de habilidades e atitudes que futuramente serão colocadas em prática (DOMINGOS, 2016, p. 174).

A pesquisa de Domingos (2016) teve uma preocupação explícita em discutir o ensino da Matemática da escola, por meio do diálogo com a prática dos licenciandos que já atuavam ou problematização com aqueles que ainda não eram professores sobre suas possíveis atitudes. Com 
isso, há a articulação entre o processo de formação e prática docente, como já preconizava Fiorentini (2005), Moreira (2012) e outros estudos.

Outra metodologia também associada à utilização de recursos da tecnologia é o Trabalho com Projetos, que foi adotado no contexto das disciplinas de Estatística (CAMPOS, 2007) e Geometria Analítica (RICHIT, 2005). Campos (2007) buscou compreender como o Trabalho de Projetos aliado à Educação Estatística pode contribuir para o desenvolvimento profissional dos estudantes que dele participaram. A pesquisadora considera que o Trabalho com Projeto contribui para que os alunos aprendam a trabalhar em grupo, compartilhar saberes e compreender os conceitos envolvidos e as suas aplicações, como mostram os excertos a seguir:

\begin{abstract}
O trabalho com projetos na sala de aula insere-se, pois, no contexto em que, de um lado, se rompe com o caráter exclusivo de obtenção do conhecimento e, por outro, se direciona o olhar pedagógico para os fundamentos de uma educação crítica e para a realização de uma aprendizagem baseada na participação ativa dos educandos a partir do estudo de situações em que se percebem as aplicações do conteúdo no cotidiano (CAMPOS, 2007, p. 70).

Percebemos a importância do Projeto quanto à possibilidade que deu aos alunos para que pudessem perceber a aplicação do conteúdo visto em sala de aula. Ao organizarmos estas reflexões, percebemos também, a necessidade que os mesmos têm de saber o "porquê" e "para quê" dos conteúdos vistos em sala de aula e a necessidade de contextualizar a teoria. O Projeto Pedagógico "Trabalho de Projetos e Educação Estatística na Universidade permite este "atuar" do aluno, na medida, que contribui para os alunos aprenderem a trabalhar em grupo, a compartilhar saberes, a compreender melhor os conteúdos e sua aplicação. Em síntese, percebemos que o processo relacional que o trabalho em grupo proporciona, faz com que os alunos apreciem esta forma de trabalhar. Também, os alunos nos sinalizam, que reconhecem a importância da colaboração entre as pessoas envolvidas no processo de constituição dos Projetos de Pesquisa (CAMPOS, 2007, p. 86).

Destacamos que estes são aspectos importantes para a construção da identidade profissional desses alunos. Consideramos que os alunos passaram a desenvolver saberes relativos ao ensino com pesquisa; saberes relacionados ao trabalho colaborativo; saberes referentes à utilização de recursos computacionais; saberes relativos à metodologia de projetos; saberes para investigação dentro de métodos estatísticos. Enfim, acreditamos que os estudantes tiveram, com a participação nesse projeto a oportunidade de desenvolverem saberes que contribuirão para sua vida profissional. De nossas análises, constatamos que o Ensino de Estatística quando associado à prática da investigação e da pesquisa se apresenta com maior significado para o aluno (CAMPOS, 2007, p. 100).
\end{abstract}

As potencialidades do Trabalho com Projetos também podem ser confirmadas por Richit (2005), que com o auxílio do software de Geometria Dinâmica Geometricks desenvolveu uma experiência direcionada a oito alunos de Licenciatura em Matemática, em recuperação na disciplina de Geometria Analítica. Seus objetivos foram promover a construção de saberes específicos da disciplina e contribuir para que os sujeitos envolvidos pudessem desenvolver saberes de uso pedagógico do software. A partir desta prática, a pesquisadora destaca a 
possibilidade de interdisciplinaridade e conexão entre os conteúdos específicos e suas aplicações em outros contextos, como pode ser verificado nos próximos excertos:

\begin{abstract}
Destacamos, a partir da experiência promovida com os sujeitos desta pesquisa e da revisão da literatura pertinente ao assunto, que 0 uso das mídias informáticas no trabalho com projetos pode auxiliar o futuro professor a perceber a relação existente entre 0 conhecimento específico adquirido ao longo da licenciatura e as possíveis aplicações destes conceitos em outras situações, além daquelas praticadas em sala de aula. Além de fazê-lo refletir sobre as formas de abordar estes conteúdos na prática pedagógica escolar (RICHIT, 2005, p. 160).

[...] avaliamos que o desenvolvimento de projetos, aliado à utilização das tecnologias informáticas, favorece a interdisciplinaridade, a formação de indivíduos criativos e com iniciativa à tomada de decisões, aspectos estes que são necessários ao exercício da profissão docente, além de contribuir para reforçar os laços de amizade, companheirismo e colaboração entre alunos e professor. Contudo, ponderamos que embora o trabalho com projetos tenha assumido um caráter disciplinar na pesquisa que foi desenvolvida, por meio do qual procurou-se obter maior aprofundamento do conteúdo de Geometria Analítica, é pertinente ressaltar que esta estratégia pedagógica favorece a interdisciplinaridade, mesmo na área de Matemática (RICHIT, 2005, p. 160).

[...] o trabalho com projetos na licenciatura pode colaborar na construção do conhecimento na área específica, no desenvolvimento de saberes de uso pedagógico das mídias informáticas e contribui para o aprofundamento do conhecimento acerca do próprio recurso que é utilizado. Para tanto, é necessário que a estratégia pedagógica adotada pelo docente, conceda aos futuros professores autonomia para explorar conceitos de uma dada área do conhecimento usando recursos das tecnologias informáticas. Dentre as atividades que se ajustam a este propósito, destacamos a produção de atividades didáticas focando conteúdos da referida área do conhecimento e a construção de sites pertinentes à uma determinada disciplina, sugerindo, além das tarefas de sala de aula, atividades que façam uso das mídias informáticas (RICHIT, 2005, p. 161).
\end{abstract}

Além disso, vemos que a pesquisa de Richit (2005) oportuniza também a articulação entre a teoria e a prática visto que, durante as atividades propostas, os alunos eram levados a refletir sobre as formas de abordar os conteúdos na prática pedagógica escolar. Nesse sentido, mesmo sem estar em contato com o ambiente escolar, o licenciando ia refletindo sobre 0 trabalho do professor, seu futuro campo de atuação.

A pesquisadora discute ainda sobre as dificuldades dos graduandos em escolher um tema para investigação ou em utilizar os recursos da tecnologia, dificuldades estas que podem estar associadas à falta de experiências educacionais na licenciatura que vivencie essas aprendizagens e dê autonomia para os alunos. Desse modo, a pesquisadora ressalta que as práticas pedagógicas na licenciatura precisam ser desenvolvidas de modo a vincular a formação tecnológica, específica e pedagógica:

Analisando o processo que permeou o trabalho com os projetos, verificamos que algumas duplas encontraram dificuldades na escolha dos temas que seriam focados em suas atividades e na integração das mídias informáticas às mesmas. 0 primeiro 
aspecto pode estar relacionado com a imaturidade destes alunos e a falta de experiências educacionais que Ihes coloquem a frente da sua aprendizagem. Com relação ao segundo aspecto, e levando em conta as reflexões de Cury (2001), consideramos que este pode ser consequência da carência de práticas pedagógicas na licenciatura que promovam o uso contextualizado desses recursos. Neste sentido, sugerimos que as práticas pedagógicas nos cursos de licenciatura sejam repensadas, de modo que as mídias informáticas sejam incorporadas à prática dos professores formadores, para que os futuros docentes aprendam a fazer uso das mesmas no contexto das suas experiências educacionais, pois não faz sentido pensar que a formação tecnológica possa ser desenvolvida desvinculada da formação específica e pedagógica (RICHIT, 2005, p. 160).

Com foco nas disciplinas de Geometria Plana, os trabalhos de Pinheiro (2012) e Ramassotti (2015) apresentam contribuições acerca do seu desenvolvimento, reforçando a utilização da régua e compasso e afirmando a contribuição do uso de softwares, como mostram os excertos a seguir:

Defendemos a ideia de que as Licenciaturas em Matemática, além de utilizarem os instrumentos régua e compasso para o ensino de Geometria Plana, deveriam oferecer disciplinas na área de tecnologia na formação de seus professores, a fim de levá-los a pensar em outros instrumentos que pudessem auxiliar na construção do raciocínio geométrico dos licenciados, visando à construção completa desse aluno (PINHEIRO, 2012, p. 147).

Os professores, em sua maioria, apontam que é importante o uso de softwares de geometria dinâmica, considerando a presença dos recursos tecnológicos uma realidade na sociedade moderna (RAMASSOTTI, 2015, p. 44).

Nossos entrevistados reconhecem as diversas possibilidades oferecidas pelos softwares, movimentação, visualização e a própria construção das figuras, entre outras (RAMASSOTTI, 2015, p. 46).

Também no contexto da disciplina Geometria Plana, a pesquisa de Freitas (2006) apresenta uma prática desenvolvida durante um semestre, com aulas teóricas e práticas. Foram propostas diversas atividades que exploravam o uso da escrita como autobiografia, cartas, bilhetes e relatórios, associadas ao uso do software Tabulae e ao desenvolvimento de projetos. Para a pesquisadora, o desenvolvimento da disciplina propôs romper com o esquema $3+1$, no qual os conteúdos matemáticos e pedagógicos são explorados separadamente:

Os momentos de escrita na disciplina, em que a forma de expressão simbólica era minimizada e substituída por uma outra mais discursiva, contribuíram para que os licenciandos liberassem seus pensamentos e produzissem reflexões sobre si mesmos (suas crenças, concepções e significações), sobre os conceitos de Geometria e, sobretudo, sobre a prática pedagógica desse conteúdo, fazendo, assim, emergir aspectos educativos e didático-pedagógicos que nem sempre são percebidos ou estão explícitos durante as aulas. A articulação necessária para o registro escrito parece resgatar novamente a experiência vivida, tornando-a diferente e, com isso, potencializando seu caráter formador e transformador (FREITAS, 2006, p. 84).

A utilização da escrita na dinâmica das aulas da disciplina "Geometria e Desenho Geométrico" evidenciava aspectos pedagógicos associados ao conteúdo específico, essenciais a futuros professores. Esses aspectos, em geral, ficam relegados, com 
maior preponderância às disciplinas dos últimos períodos do curso de formação, em especial as disciplinas de Prática e Estágio (FREITAS, 2006, p. 85).

[...] apesar de a maioria dos alunos reconhecer uma certa inabilidade para se comunicar via escrita discursiva, muitos deles identificaram os benefícios da inserção dessas diferentes formas de linguagem no curso, dando destaque à sua contribuição para a formação do educador. Houve alunos que despertaram para a oportunidade que a escrita oferece de revisitar as ideias, considerando que 0 registro escrito contribui para a aprendizagem, uma vez que disseram que, ao reler e corrigir alguns pontos que sejam necessários, descobriram seus próprios erros e os corrigiram (FREITAS, 2006, p. 148).

Essa intervenção favoreceu a aquisição de uma postura que permitia aos futuros professores estarem continuamente abertos à problematização e à (re)significação de valores, em especial quanto ao papel da avaliação, da abertura de diálogo e de concepções, sobretudo relativas ao encaminhamento para se chegar ao rigor e à linguagem específica da Matemática (FREITAS, 2006, p. 276).

Destacamos também o método de avaliação utilizado na disciplina, que foi baseado nas atividades semanais de laboratório e no projeto em dupla, com datas predefinidas para apresentação e discussão do pré-projeto, entrega do texto escrito e apresentação oral do mesmo. Esse projeto tinha por objetivos criar uma proposta de atividade de laboratório, para alunos do Ensino Fundamental ou Médio, envolvendo a Geometria; registrar por escrito o processo de criação, o material produzido e uma solução para a proposta apresentada; além de apresentar oralmente o material desenvolvido e compartilhar ideias com a classe.

Essa prática apresentada por Freitas (2006), mais uma vez, mostra uma disciplina de conteúdo matemático articulada com a prática docente do futuro professor. Além disso, foi uma prática que contribuiu para além do aprendizado na disciplina, influenciando a prática docente dos futuros professores, como mencionado pela pesquisadora:

[...] a experiência discente com a escrita discursiva sobre a Matemática, na formação inicial influenciou a prática futura dos professores, pois estes passaram também a explorá-la didático-pedagogicamente com seus alunos (FREITAS, 2006, p. 273).

Várias das abordagens metodológicas ou práticas pedagógicas, apresentadas pelas teses e dissertações, relacionaram-se com a utilização de recursos tecnológicos como os softwares Geometricks, GeoGebra e Tabulae, os quais assumiram um papel importante para a contribuição das práticas desenvolvidas na formação dos licenciandos. Entretanto, como apresentado no trecho a seguir, retirado da pesquisa de Ramassotti (2015), a máquina não substitui a ação humana e assim a contribuição e as potencialidades do uso de softwares, e de outras ferramentas, depende diretamente da maneira como isso é realizado.

O interessante é observar que, na opinião de Wladimir e Geraldo, implicitamente, máquina ou software nenhum substitui a ação humana, nesse caso, a do professor. 
[...] Nesse sentido, acreditamos que o professor precisa ter conhecimento do conteúdo, caso contrário terá dificuldade de realizar atividades utilizando o computador (RAMASSOTTI, 2015, p. 273).

Essa questão vai em direção ao que preconiza Miskulin e Silva $(2010$, p. 6) quando defendem que "não basta a adoção de novas técnicas ou de um novo artefato tecnológico; importa o uso que dele fazemos". De fato, a utilização de um software deve estar acompanhada de atividades que incentivem uma exploração e investigação dos conceitos envolvidos.

De modo geral, tais práticas pedagógicas e abordagens metodológicas constituem-se em um novo cenário de aprendizagem para as disciplinas de conteúdo matemático, no qual são privilegiadas e incentivadas a exploração e investigação dos conceitos, e muitas vezes, a visualização dos conceitos e aplicações. A construção desse ambiente foi possível também pela utilização de recursos tecnológicos como os softwares Geometricks, GeoGebra e Tabulae, que associados à metodologia de Trabalho com Projetos, Modelagem Matemática, atividades investigativas, entre outras, constituíram-se como um fator potencializador para a aprendizagem dos conteúdos das disciplinas, saberes associados ao ensino da Matemática e uso pedagógico dos softwares para o ensino.

Algumas das teses e dissertações deixam transparecer ainda uma articulação entre os conteúdos matemáticos e os pedagógicos, na medida que se preocupam com o ensino da Matemática escolar ou trabalham em parceria com outras disciplinas, como aconteceu na pesquisa de Freitas (2006), que estabeleceu uma parceria com a disciplina de Prática de Ensino. Estas contribuições vão ao encontro ao que afirmam Fiorentini (2005), Moreira e David (2005), Moreira (2012), Pais (2014), entre outros autores, uma vez que essas práticas oferecem também uma formação pedagógica ao professor de Matemática.

Entendemos que práticas pedagógicas como essas podem ser desenvolvidas em disciplinas de conteúdo matemático do curso de Licenciatura em Matemática, adequando-as aos contextos de cada curso. Contudo, ressaltamos que o desenvolvimento de tais práticas impõe novos desafios à formação de professores. Como mencionado por Schultz (2015), um dos desafios de sua proposta foi a baixa participação e a dificuldade dos alunos no desenvolvimento dos projetos de Modelagem Matemática, como mostra o excerto a seguir:

Quanto ao desenvolvimento e envolvimento dos alunos nos projetos de MM, pode-se inferir, que apenas dois grupos (cinco alunos) dedicaram-se efetivamente na execução dos seus projetos (SCHULTZ, 2015, p. 93). 
A dificuldade por parte dos alunos também foi mencionada por Richit (2005) e entendemos que possa ter acontecido ainda em outros contextos investigados. No entanto, esse desafio pode e deve ser enfrentado na formação de professores, por meio da ampliação de práticas, as quais estão sendo relatadas nas pesquisas, de modo que os licenciandos se sintam motivados e instigados a envolverem-se com esse tipo de atividade.

Apontamos ainda o fato de que a maioria delas foram desenvolvidas em paralelo com a disciplina investigada, beneficiando apenas alunos que se dispuseram ou puderam participar. Deste modo, mais uma vez, há o desafio de que essas práticas sejam levadas para dentro das disciplinas de conteúdo matemático. Isso não significa que todas as aulas ou todos conteúdos abordados em uma disciplina precisam acontecer dessa forma, mas que são experiências que podem ser adotadas em determinados momentos.

Sabemos que o desenvolvimento das disciplinas de conteúdo matemático exclusivamente para a Licenciatura em Matemática, ou seja, separado de outros cursos, configura-se como um desafio para a formação de professores e depende de outros fatores como demanda de professores, espaços, entre outras questões. Ainda assim, pontuamos a relevância de se pensar nesta questão, levando-se em consideração a importância de uma formação satisfatória e específica para o professor como menciona Moreira (2012).

\section{Considerações}

Neste artigo apresentamos práticas pedagógicas desenvolvidas no contexto de disciplinas de conteúdo matemático dos cursos de Licenciatura em Matemática, realizadas por algumas das teses e dissertações analisadas para a pesquisa de mestrado em desenvolvimento. A partir destas práticas, evidenciamos aspectos matemáticos, didáticos e pedagógicos das disciplinas e discutimos acerca de suas contribuições e desafios para a formação inicial de professores.

De modo geral, as práticas pedagógicas são apoiadas na utilização de softwares, associadas à metodologia de Trabalho com Projetos, Modelagem Matemática, atividades investigativas, entre outras. Os resultados das teses e dissertações mostram que estas constituíram como um fator potencializador para a aprendizagem dos conteúdos das disciplinas e para a construção de saberes associados ao ensino da Matemática e uso pedagógico dos softwares no ensino.

Assim, ainda com os desafios de implantação nos cursos de licenciatura atuais, por fatores como as ementas das disciplinas pré-estabelecidas e desenvolvimento conjunto dessas disciplinas 
com outros cursos, destacamos as suas contribuições para a formação do professor e para estreitamento da relação entre a formação e a prática.

Por fim, entendemos que o trabalho realizado pode servir como um instrumento de estudo para professores que atuam na licenciatura e para discussões acerca da organização dos cursos, considerando, com base em Grando e Miskulin (2018), o atual momento de implantação das novas diretrizes (BRASIL, 2015) para a formação de professores.

\section{Referências}

BARBOSA, Jonei Cerqueira. Modelagem na Educação Matemática: contribuições para o debate teórico. In: REUNIÃO ANUAL DA ASSOCIAÇẪO NACIONAL DE PÓS-GRADUAÇÃO E PESQUISA EM EDUCAÇÃO, 24, 2001, Caxambu. Anais da XXIV Reunião Anual da ANPED. Caxambu: ANPED, 2001, p. 1-15.

BARDIN, Laurence. Análise de conteúdo. Tradução de Luís Antero Reto e Augusto Pinheiro. Lisboa: Edições 70, 1977.

BENITES, Vanessa Cerignoni. Formação de professores de Matemática: dimensões presentes na relação PIBID e comunidade de prática. 2013. 124f. Dissertação (Mestrado em Educação Matemática) - Instituto de Geociências e Ciências Exatas. Universidade Estadual Paulista. Rio Claro.

BRASIL. Resolução CNE/CP 2, de 1 de julho de 2015. Define as Diretrizes Curriculares Nacionais para a formação inicial em nível superior (cursos de licenciatura, cursos de formação pedagógica para graduados e cursos de segunda licenciatura) e para a formação continuada. Brasília: Diário Oficial da União, 2 de julho de 2015, seção 1, p. 8-12.

CAMPOS, Sandra Gonçalves Vilas Bôas. Trabalho de projetos no processo de ensinar e aprender Estatística na universidade. 2007. 148p. Dissertação (Mestrado em Educação) - Faculdade de Educação. Universidade de Uberlândia. Uberlândia.

CASTRO, Amélia Domingues de. A licenciatura no Brasil. Revista de História, São Paulo, v. 50, n.100, p. 627-652, out./dez. 1974.

DIOGO, Maria das Graças Viana Sousa. Uma abordagem didático-pedagógica do Cálculo Diferencial e Integral I na formação de professores de Matemática. 2015. 256f. Tese (Dourado em Educação Matemática) - Instituto de Geociências e Ciências Exatas, Universidade Estadual Paulista, Rio Claro.

DOMINGOS, Rônero Márcio Cordeiro. Resolução de Problemas e Modelagem Matemática: uma experiência na formação inicial de professores de Física e Matemática. 2016. 194f. Mestrado (Ensino de Ciências e Educação Matemática) - Centro de Ciências e Tecnologia. Universidade Estadual da Paraíba. Campina Grande.

FIORENTINI, Dario, PASSOS, Carmem Lúcia Brancaglion; LIMA, Rosana Catarina Rodrigues. (Org.) Mapeamento da pesquisa acadêmica brasileira sobre o professor que ensina Matemática: período 2001 a 2012. Campinas: FE-Unicamp, 2016. 
FIORENTINI, Dario. A formação matemática e didático-pedagógica nas disciplinas da Licenciatura em Matemática. Revista de Educação PUC-Campinas, Campinas, n. 18, p.107-115, jun. 2005.

FREITAS, Maria Tereza Menezes. A escrita no processo de formação contínua do professor de Matemática. 2006. 299f. Tese (Doutorado em Educação) - Faculdade de Educação. Universidade Estadual de Campinas. Campinas.

GATTI, Bernardete Angelia. Formação de professores no Brasil: características e problemas. Educação \& Sociedade, Campinas, v. 31, n. 113, out./dez. 2010.

GOLDENBERG, Mirian. A arte de pesquisar: como fazer pesquisa qualitativa em ciências sociais. 8. ed. Rio de Janeiro: Record, 2004.

GONÇALVES, Daniele Cristina. Aplicações das derivadas no Cálculo I: atividades investigativas utilizando o GeoGebra. 2012. 110f. Dissertação (Mestrado em Educação Matemática) - Instituto de Ciências Exatas e Biológicas. Universidade Federal de Ouro Preto. Ouro Preto.

GRANDO, Regina Célia. MISKULIN, Rosana Giaretta Sguerra. Pesquisas em formação inicial e continuada de professores que ensinam Matemática sob a perspectiva da articulação entre 0 conhecimento do professor e a prática. Perspectiva, Florianópolis, v. 36, n. 2, p. 396-398, abr./jul. 2018.

GRILO, Jaqueline de Souza; BARBOSA, Jonei Cerqueira; LUNA, Ana Virgínia de Almeida. Repercussões de disciplinas específicas na ação do professor de Matemática da educação básica: uma revisão sistemática. Educação Matemática Pesquisa, São Paulo, v. 17, n. 1, p. 4-24, jan./abr. 2015.

KLEIN, Felix Christian. Matemática elementar de um ponto de vista superior. v. I, parte I Aritmetica. Lisboa: Sociedade Portuguesa de Matemática, 2009.

MAZZI, Lucas Carato. Experimentação-com-Geogebra: revisitando alguns conceitos da Análise Real. 2014. 137f. Dissertação (Mestrado em Educação Matemática) - Instituto de Geociências e Ciências Exatas. Universidade Estadual Paulista. Rio Claro.

MISKULIN, Rosana Giaretta Sguerra; ESCHER, Marco Antonio; SILVA, Carla Regina Mariano. A prática docente do professor de Matemática no contexto das TICs: uma experiência com a utilização do MAPLE em cálculo diferencial. Revista de Educação Matemática, São Paulo, v. 10, p. 29-37, 2007.

MISKULIN, Rosana Giaretta Sguerra; SILVA, Mariana da Rocha. Corrêa. Curso de Licenciatura em Matemática a Distância: uma realidade ou uma utopia? In: JAHN, Ana Paula; ALLEVATTO, Norma. (Org.). Tecnologias e Educação Matemática: ensino, aprendizagem e formação de professores. Recife: SBEM, 2010. p. 105-124.

MOREIRA, Plínio Cavalcante. $3+1$ e suas (in)variantes: reflexões sobre as possibilidades de uma nova estrutura curricular na licenciatura em Matemática. Bolema, Rio Claro, v. 26, n. 44, p. $1137-$ 1150, dez. 2012

MOREIRA, Plínio Cavalcante; DAVID, Manuela Martins Soares. A formação matemática do professor: licenciatura e prática docente escolar. Belo Horizonte: Autêntica, 2005. 
ONUCHIC, Lourdes de la Rosa; MORAIS, Rosilda Santos. Resolução de Problemas na formação inicial de professores de Matemática. Educação Matemática Pesquisa, São Paulo, v. 15, n. 3, p. 671-691, set./dez. 2013.

PAIS, Luiz Carlos. Uma abordagem praxeológica da prática docente na Educação Matemática. IX ENCONTRO NACIONAL DE EDUCAÇÃO MATEMÁTICA. Anais do IX ENEM: Belo Horizonte: SBEM, 2007, p. 65-78.

PASSOS, Carmem Lúcia Brancaglion; et al. Desenvolvimento profissional do professor que ensina Matemática: uma meta-análise de estudos brasileiros. Quadrante, Lisboa, v. 25, n. 1 e 2, p.193219, 2006.

PINHEIRO, Ana Cláudia Mendonça. A mediação docente na construção do raciocínio geométrico de alunos da licenciatura em Matemática na disciplina Desenho Geométrico. 2008. 184f. Dissertação (Mestrado em Educação) - Faculdade de Educação. Universidade Estadual do Ceará, Fortaleza.

PONTE, João Pedro da. Formação do professor de Matemática: perspectivas atuais. In: PONTE, João Pedro da. (Org.) Práticas profissionais dos professores de Matemática. Lisboa: Instituto de Educação da Universidade de Lisboa, 2014, p. 343-358.

PONTE, João Pedro; BROCARDO, Joana; OLIVEIRA, Hélia. Investigações matemáticas na sala de aula. 2. d. Belo Horizonte: Autêntica, 2003.

RAMASSOTTI, Luiz Carlos. A Geometria Euclidiana na licenciatura em Matemática do ponto de vista de professores formadores. 2015. 179f. Dissertação (Mestrado em Educação Matemática) Instituto de Geociências e Ciências Exatas. Universidade Estadual Paulista. Rio Claro.

RICHIT, Adriana. Projetos em Geometria Analítica usando software de Geometria dinâmica: repensando a formação inicial docente em Matemática. 2005. 169f. Dissertação (Mestrado em Educação Matemática) - Instituto de Geociências e Ciências Exatas, Universidade Estadual Paulista, Rio Claro.

SANTOS, Ivan Nogueira. Explorando conceitos de Geometria Analítica Plana utilizando Tecnologias da Informação e Comunicação: uma ponte do Ensino Médio para o Ensino Superior construída na formação inicial de professores de Matemática. 2011. 163 p. Dissertação (Mestrado em Educação Matemática) - Instituto de Ciências Exatas e Biológicas. Universidade Federal de Ouro Preto. Ouro Preto.

SCHULTZ, Caroline. Modelagem Matemática e recursos tecnológicos: uma experiência em um curso de formação inicial de professores. 2015. 127f. Dissertação (Mestrado em Educação Matemática e Ensino de Física) - Centro de Ciências Naturais e Exatas. Universidade Federal de Santa Maria. Santa Maria.

VALENTE, José Armando. Blended learning e as mudanças no ensino superior: a proposta da sala de aula invertida. Educar em Revista, Curitiba, n. 4, 2014. 